\title{
Study of mechanisms responsible for foaming-agent loss in porous media at high-temperature conditions
}

Mecanismos que ocasionan pérdidas de agente espumante en medio poroso en condiciones de alta temperatura

\section{Yulian Fernando Rodríguez-Pantoja (iD ${ }^{1 *}$, Ana Paula Villaquirán-Vargas (iD) ${ }^{1}$, Samuel Fernando Muñoz-Navarro (iD) 1}

${ }^{1}$ Grupo de Investigación GRM, Escuela de Ingeniería de Petróleos, Facultad de Ingenierías Fisico-químicas, Universidad Industrial de Santander. Cra 27 Calle 9 Ciudad Universitaria. C. P. 680002. Bucaramanga, Colombia.

\section{CITE THIS ARTICLE AS:}

Y. F. Rodríguez, A. P.

Villaquirán and S. F.

Muñoz. "Study of

mechanisms

responsible for

foaming-agent loss in

porous media at high

temperature

conditions", Revista

Facultad de Ingeniería

Universidad de

Antioquia, no. 102, pp.

62-76 Jan-Mar 2022.

[Online]. Available:

https : //www.doi.

org/10.17533/udea.

redin. 20200700

\section{ARTICLE INFO:}

Received: January 21, 2019

Accepted: July 25

2020

Available online: July

28,2020

\section{KEYWORDS:}

Petroleum industry; chemical technology; chemical analysis; organic chemistry

$>$ Industria petrolera; tecnología química; análisis químico; química orgánica
ABSTRACT: Steam-foam processes require the correct selection of a surfactant agent resistant to high temperatures, stable over time, and capable of producing mobility reduction of the steam. A state-of-the-art revision allows identifying the main phenomena that could cause surfactant loss in porous medium. These phenomena are phase partitioning, adsorption, and thermal degradation, where phase partitioning could cause higher loss. Additionally, adsorption and phase partitioning have a direct relationship with the surfactant concentration below its critical micellar concentration. Reservoir conditions such as temperature, salinity and presence of clay are parameters that influence surfactant solution behavior. High temperatures in porous medium could reduce tensoactive loss by adsorption due to exothermic reactions. However, the foaming agent could be partitioned into oleic phase owing to viscosity reduction and molecules motion improvement towards crude oil. High concentrations of salt could increase adsorption measurements, produce surfactant preference to oil or even precipitation. Surfactant solution should be formed by a mixture of components that provides stability during the steam injection process. Generally, the solution is composed mainly of an anionic surfactant. Some widely used surfactants are alkyl aryl sulfonates and alpha olefin sulfonates, suitable for steam procedures up to $300^{\circ} \mathrm{C}$. Despite, non-ionic surfactants, and $\mathrm{pH}$ adjustment substance could be added to give foaming agent an improved performance.

RESUMEN: Los procesos de inyección vapor-espuma requieren de la selección de un agente surfactante resistente a altas temperaturas, estable durante el tiempo y que reduzca la movilidad del vapor. La revisión del estado del arte permite identificar los principales fenómenos que producen pérdida de tensoactivo. Estos fenómenos son partición de fase, adsorción y degradación térmica, en donde el fenómeno de partición podría llegar a ser el más problemático. La adsorción y partición presentan un comportamiento directamente relacionado con la concentración micelar crítica del surfactante; además de verse afectadas por ciertas condiciones del yacimiento como lo son la temperatura, la salinidad y la presencia de arcillas. Las altas temperaturas podrían reducir la pérdida del tensoactivo en el caso de la adsorción; sin embargo, en la partición aumentaría la preferencia del agente a la fase oleica debido a la reducción de la viscosidad del aceite. Las altas concentraciones de sal podrían aumentar la adsorción, producir una inversión de fase o incluso la precipitación del surfactante. El agente debe estar conformado por una mezcla de componentes que le proporcionen estabilidad. Generalmente, la solución está compuesta principalmente por surfactantes aniónicos. Los surfactantes ampliamente usados son los alquíl aríl sulfonatos y los sulfonatos de alfa olefina, estables hasta $300^{\circ} \mathrm{C}$. No obstante, existen componentes que pueden ser añadidos para mejorar su rendimiento, como lo son los surfactantes no iónicos o sustancia reguladoras de $\mathrm{pH}$.

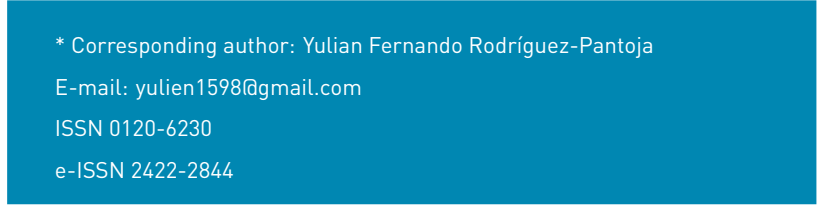

\section{Introduction}

Enhance Oil Recovery (EOR) contain various technologies that aim to increase oil recovery factor of the prospective 
reservoir. Among the thermal EOR processes are those that include steam injection, which have been the most applied to reservoirs so far. Approximately, there is information about 1,028 wells where steam operations have been applied [1]. Despite obtaining promising results in the recovery factor, up to $60 \%$ [2], there are certain problems that delay adequate steam distribution in the porous medium.

Certain steam injection processes, as Steam Flooding and Cyclic Steam Stimulation, could be improved with solvents, foams, gels, or even miscible and immiscible gases [3]. For this study, steam-foam injection is considered. The foaming agent is composed mainly of surfactants and its main goal is correcting steam distribution in the reservoir by steam flow redirection to non-preferential flow areas.

The steam-foam injection procedure assessment for reservoir applications should consider surfactant stability over the time at steam injection normal temperatures $[4,5]$. Although surfactant loss cannot be completely reduced, it can be controlled. Therefore, it is important to identify and select a suitable tensoactive with the proper molecular characteristics. Besides, establishing the different phenomena that cause agent decomposition will allow defining basic criteria to accomplish foam formation in situ.

In the steam-foam state of art, several experimental evaluations and results are registered that enable to identify common behaviors of diverse foaming agents at reservoir conditions. However, it is necessary to determine the most used surfactants in the preparation of the foams. Additionally, description and analysis of the dominant physic-chemical in surfactant loss will allow considering these phenomena for future steam project. These are basically the objectives of this article.

\section{Surfactant}

A surfactant is a surface-active substance that reduces the surface tension. They are usually organic compounds that are amphiphilic, meaning they are composed of a hydrocarbon chain and a polar hydrophilic group [6]. Therefore, they are soluble in both organic solvents and water [7]. It is possible to classify surfactants depending on head ionic nature; in this way, there are cationic, anionic, nonionic, and finally amphoteric, or also zwitterionic, tensoactives [8,9]. Design and selection of chemical structure and composition of tensoactive chemical structure and composition must be implemented to ensure a correct functioning in porous media, reducing uncertainty and future problems. Some reservoir conditions as temperature and pressure should be considered for experimental evaluation and selection
[10].

The selection of surfactant in EOR processes depends on their performance and stability in porous medium; in case of cationic surfactants, they tend to generate greater adsorption on sandstones walls by electrostatic interaction between positive electric charge that molecules possess and the negative character of the rock. The kinetics of adsorption mainly depends on the nature of the adsorbent and the surfactant type. If the surfactant and the adsorbent are oppositely charged the rate of adsorption is fast [2]. To be more specific, in cationic and amphoteric surfactants, there are cation exchanges between them and sand formations, this is because sodium monovalent cation could transfer charges with clays that possess divalent cation, resulting in a divalent cation increase in aqueous phase. Therefore, this increase could cause excessive tensoactive precipitation and adsorption in sandstones that retard and reduce foam solution propagation profile [11]. Consequently, anionic surfactants would reject an interaction with the rock due to their negative electric charge, being useful to use in these formations.

\subsection{Foaming agents}

Foam is a gas/liquid dispersion, with gas such an internal phase for an external liquid phase. Foam quality is the ratio of gas volume to foam volume (volumetric gas content) at a given pressure and temperature [12]. Foam is formed during steam injection and prevents steam overrides to upper layer, thereby it improves steam sweep efficiency [13]. Some parameters must be treated when steam-foam injection processes are planned, these are the following:

- Fluid-fluid or fluid-rock interactions in reservoir. The surfactant should be able to interact with reservoir substances as brines, hydrocarbons, and minerals, without affecting foam stability.

- Being stable at high temperatures.

- Foam durability. It refers to the time average that foaming agent remain formed in reservoir [14].

- Average size of gas bubbles. A small size is required because resistance to flow in rock matrix.

- Mobility reduction capacity. Foam positioning in the preferential flow zones to redirect steam to new zones [15].

Regarding to surfactants that have been used in petroleum industry, there are some surfactant types stable at high temperature conditions [16]. Foaming agents will work jointly with a thermal EOR operation, then this substance should remain stable in reservoir along recovery process. Tensoactives tend to suffer side effects due to thermal degradation phenomena, where kinetic chemical reactions 
occur and change surfactant initial design in compounds with different characteristics that are not suitable for steam injection processes.

The requisite of being thermally stable discard several tensoactives. This is the case of many nonionic surfactants or even anionic surfactants such as alcohol sulfates and ethoxy sulfates which tend to decompose rapidly at temperatures greater than $100^{\circ} \mathrm{C}$ [17]. However, an important surfactant group is well-known for having agents thermally stable, these are the sulfonates. There are some results allowing to determine which sulfonates show the best stability at high temperatures [18]. Although sulfonate group is quite general, there are just some sulfonates that can be used as foaming gents at high temperatures. Therefore, sulfonates definition and designing at reservoir conditions becomes the first activity to do when a steam-foam injection is considered

\section{Sulfonates}

Organic chemistry define sulfonate as an anionic ion that contains the functional group S03- [19]. Figure 1 shows the molecular structure of a typical sulfonate group, where $\mathrm{R}$ corresponds to the respective organic group that is joined to the ion.

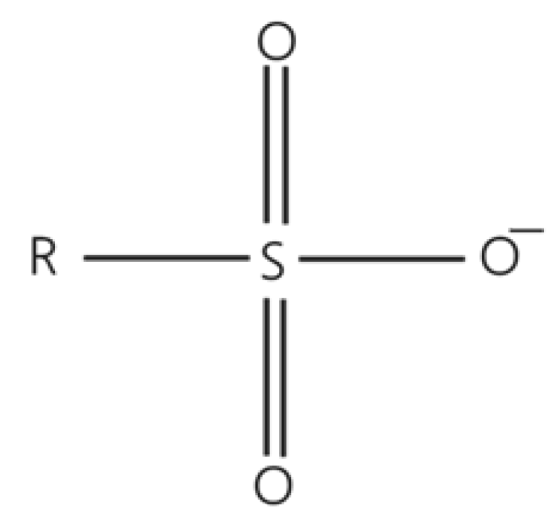

Figure 1 Schematic sulfonate molecular structure [19]

Inside a sulfonate group, there are different thermally stable surfactants. These are known because its forming foams ability, alpha olefin sulfonates and alkyl aryl sulfonates belong to these subgroups and are stable at temperatures above $200^{\circ} \mathrm{C}$ [17].

There is another parameter to consider for a foaming agent design, the steam mobility reduction. This feature is selected to improve steam distribution in the porous media. In-situ foaming during steam-foam injection modifies steam profiles and thus helps to decrease the steam override. All this is because ability of foam to flow like a liquid and remain immobile like a solid. [20, 21].
Carbon chains can be linear or branched, this organization could affect surfactant mobility reduction in reservoir because isomeric components modify surfactant features. Although an agent has a similar molecular formula, its molecular ordering will generate different tensoactive properties. Linear molecular structures tend to be suitable foaming agent because they generate a representative mobility reduction, this is since differential pressure observed in experimental test was more representative in linear surfactants [17]. In Figure 2, linear molecular and branched molecular structures are shown.

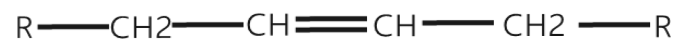

(a)

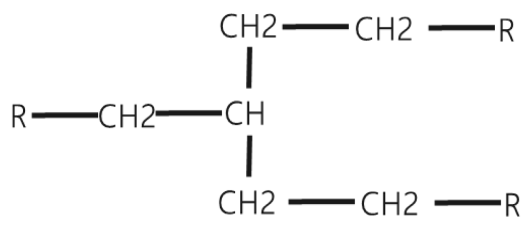

(b)

Figure 2 Schematically. (A) Linear molecular arrangement. (B) Branched molecular arrangement [17]

Regarding to alpha olefin sulfonates those with an appropriate performance in terms of thermal stability and mobility reduction are mono-sulfonates and linear di-sulfonates. On the other hand, inside alkyl aryl sulfonates, the mono-chain and the di-chain show a more promising result performance than their branched counterparts, these behaviors were all conducted at temperatures higher than $215^{\circ} \mathrm{C}$ [17]. However, it is important to consider that surfactant mobility reduction is highly influenced by temperature, it means that tensoactives that effectively reduce the steam mobility at low temperature not necessarily are successful at high temperatures and vice versa.

The success of the process also strongly depends on the strength and stability of the foam, which is related to the surfactant composition and salinity [22]. According to foam thermal stability measurements at $200^{\circ} \mathrm{C}$ and 30 bars, it shows a half-life foam representative for different mixes of alpha olefin sulfonates and alkyl aryl sulfonates [23].

\section{Alpha olefin sulfonates}

Alpha Olefin Sulfonates (AOS) are characterized by containing in their molecular structure a double bond between two carbons. Figure 3 shows a schematic molecular structure of a typical AOS. 


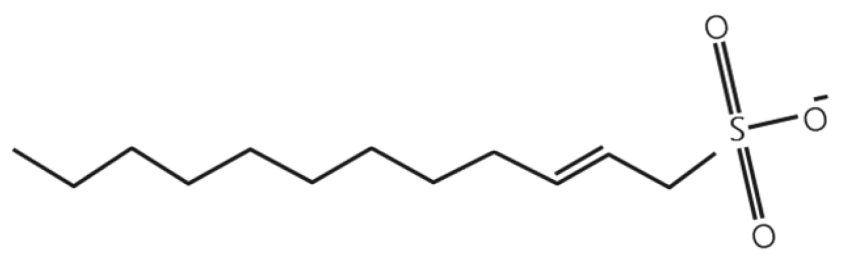

Figure 3 Schematic molecular structure $\mathrm{AOSC}_{12}$ [24]

Lau \& Borchardt, compared two AOS surfactant tests results, the first AOS with a chain length average of 24-26 carbons per molecule and the second AOS with a chain length average of 16-18 carbons per molecule. It was possible to define that there was an improvement in surfactant propagation rate, foam resistance and residual oil saturation reduction when carbons number in surfactant molecule was greater. Then, linear chain size (amount of carbons) influence directly tensoactive performance. Besides, it was determined that a longer chain produce a higher mobility reduction [17]. It is shown in Figure 4, where AOS tensoactives were also compared in terms of mobility reduction factor and molecular chain length.

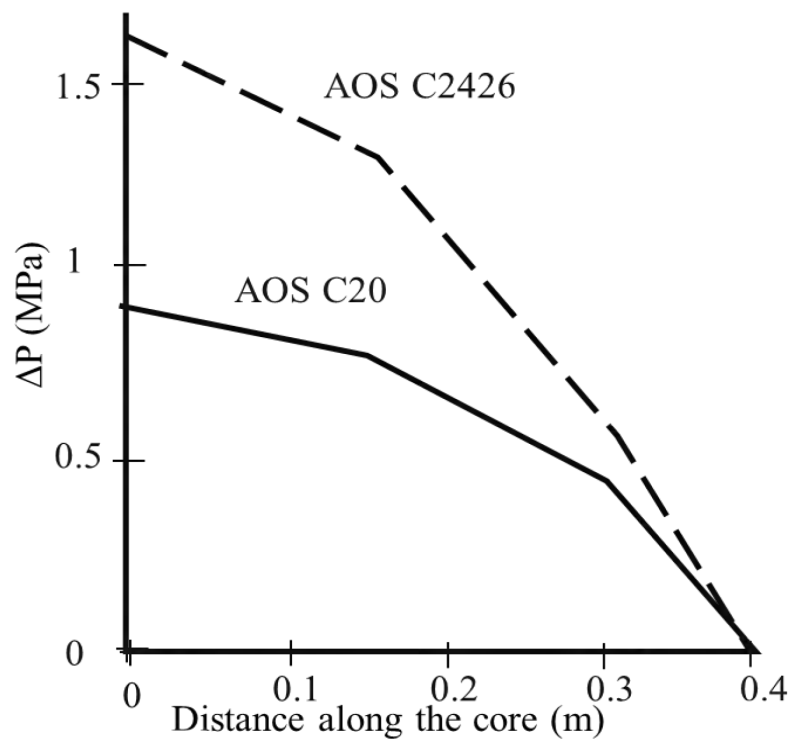

Figure 4 Pressure variation as a function of core distance in a displacement for AOS [25]

\section{Alkyl aryl sulfonates}

Each alkyl aryl sulfonate (AAS) molecule is formed by an aromatic functional group, generally an aromatic hydrocarbon. Inside aromatic functional groups, there are two clear examples of widely used aromatic groups on petroleum industry, these are benzene and toluene. In the case of AAS, there is a specific nomenclature based on aromatic group and molecular structure, one example of this is toluene. AAS form by toluene are of two types, branched alkyl-toluene (ATS) and lineal alkyl-toluene sulfonates (LTS). Figure 5 shows a schematic molecular structure of a typical LTS. AAS surfactant performance as foaming agents also depends on molecular carbons number.

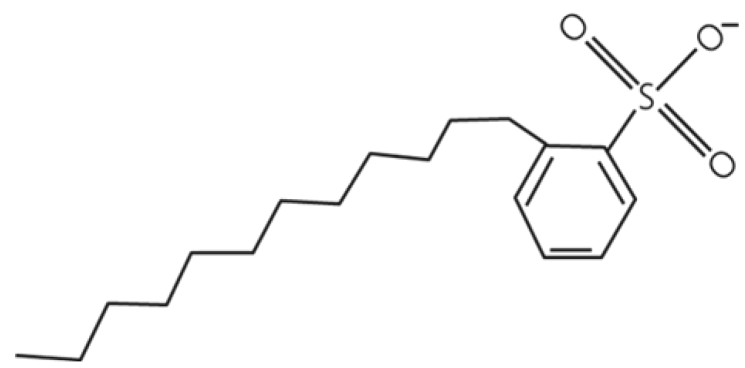

Figure 5 Schematic molecular structure LTSC12 [25]

According to Muijs et al., experiments, LTS with 20-24 and 24-28 carbons per molecule have a better mobility reduction profile at high temperatures compared to its counterparts of 18 carbons or less, it is shown in Figure 6.

\section{Phenomena}

To successfully develop a steam-foam injection process in reservoir, it is necessary to identify the principal phenomena that could generate surfactant loss in porous media. The focus is on keep surfactant stability as much as possible for foam formation and subsequent steam distribution improvement.

\subsection{Adsorption}

Adsorption describes a process in which a substance accumulates on a surface known as an adsorbent, resulting in formation of gaseous or liquid aggregation on surface of a solid or liquid body known as adsorbate [26]. Besides mobility reduction ability, low adsorption onto reservoir rock is another property of an effective surfactant [8]. Surfactant adsorption on reservoir minerals must be avoided since it contributes to undesirable reagent loss [27]. In complex processes like core flooding or reservoir injections, adsorption could be associated also with component adherence on rock surface, and it causes material losses and modification on original properties of the colloidal system. In surfactant-water-solid systems, the amount of adsorption of surfactant onto a solid phase is a function of the surfactant concentration, surface area of the solid, and temperature [28].

Adsorption development will occur until energy reaches a minimum, substrate is saturated or adsorbed molecules 


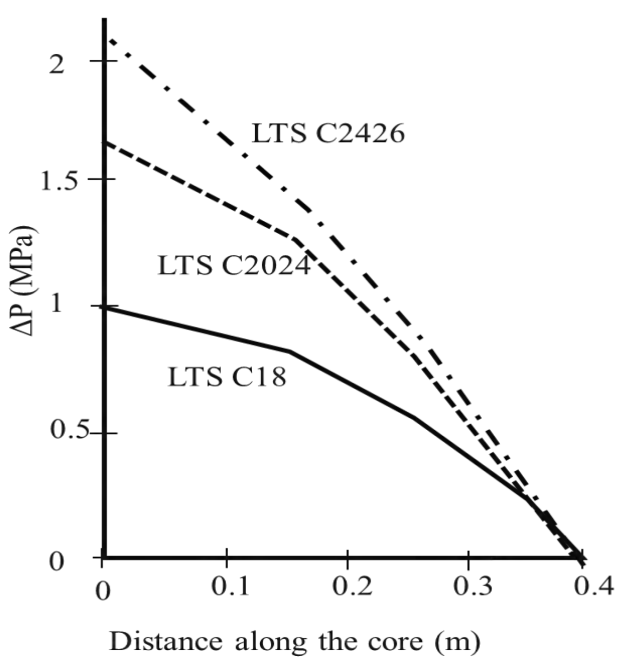

(a)

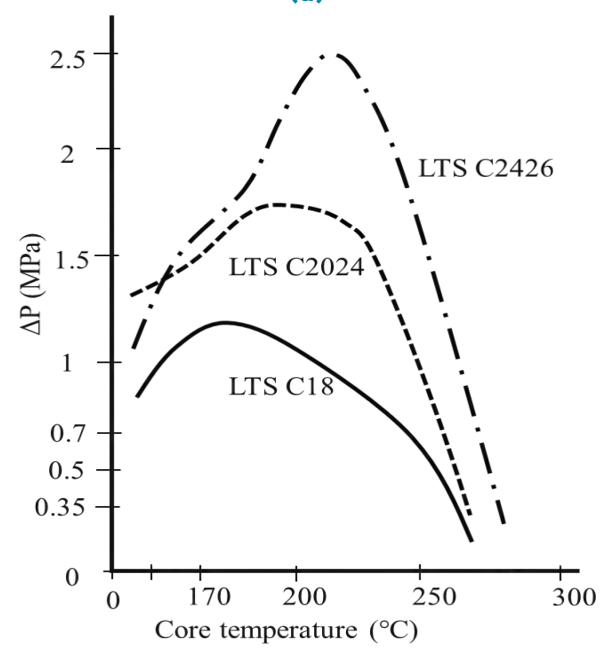

(b)

Figure 6 Pressure variation as a function of $(A)$ core distance in a displacement and (B) Temperature [17]

accumulation produces opposite forces, there is when adsorption reaches an equilibrium [29]. Interactions determination is important due to its influence on adsorption. Tensoactives possess hydrophilic-lipophilic affinity, therefore the relative magnitudes of the liquid-adsorbate and solid-adsorbate interactions will determine the extent of adsorption at a given concentration [30]. Numerous parameters will cause adsorption increasing or reducing, within these criteria are adsorbent surface charge, $\mathrm{pH}$, medium ionic strength, and hydrophilic surfactant group nature [31]. Surfactants are particularly sensitive to interactions between charges, specifically to the interchangeable mobile ion interactions with charged groups on rock surface [32].

At equilibrium, that is under isothermal static conditions, the amount of adsorption of surfactant onto a solid is a function of concentration only. Adsorption of the chemical species from a surfactant solution onto a solid surface could be understood as a competition between solute and solvent for the available adsorption sites on the solid surface [28].

Literature indicates that the Langmuir model can be applied to surfactant dilute solution in porous media at a high temperature condition, Equation 1 [33]. Despite the increasing number of recent developments for modeling equilibrium adsorption phenomena, the Langmuir isotherm remains popular [34]. Langmuir isotherm model could be applied for diluting surfactant solutions in porous medium at high temperatures. As reported by Ziegler \& Handy, static adsorption tests at high temperature conditions were conducted on a variety of anionic surfactants those which would yield isotherms capable of being described by Langmuir model. Adsorption isotherms refer to a series of adsorption measurements performed at a given temperature and whose results are plotted as a relationship between adsorbed and non-adsorbed amounts [34, 35].

$$
\theta=\frac{K_{L} * C e}{1+K_{L} * C e}
$$

$\theta=$ Fractional occupancy of the adsorption sites

$\mathrm{Ce}=$ Solute concentration

$K_{L}=$ Langmuir equilibrium constant

\section{Adsorption and concentration}

Evaluation of adsorption phenomenon allows identifying two essential aspects due to surfactant concentration, adsorption kinetics and the amount of surfactant adsorbed onto the solid surface. According to the evaluation of mixed surfactant systems reported by Trogus et al. Adsorption maxima occurs at concentrations higher than the CMC and the total amount adsorbed varies with concentration. Figure 7 plots the variation of adsorption as concentration changes, adsorption increases sharply until reaching critical micellar concentration (CMC). CMC is defined as surfactant concentration wherefrom micelles are formed spontaneously [36].

A typical isotherm usually shows four regions [2, 37]. Region 1 which occurs at lower surfactant concentration and monomers are adsorbed onto substrate due to electrostatic interaction between the head group and surface of the adsorbent. In region 2, there is a sharp increase in adsorption due the formation of surface aggregates, called colloids, these surface aggregates are formed due to lateral interactions between hydrocarbon chains and surface monomers. In region 3 , the adsorption increases with a lower gradient, because in this region the solid surface is electrically neutralized by the adsorbed surfactant monomers and adsorption takes place due 
to lateral interactions only. In region 4, the surfactant reaches $\mathrm{CMC}$; therefore, any further increase in surfactant concentration contributes to the micellization in solution and hence adsorption is constant [37]. It is possible to define that there is a maximum adsorption near CMC and subsequently an adsorption value that tends to stabilize at a constant [38].

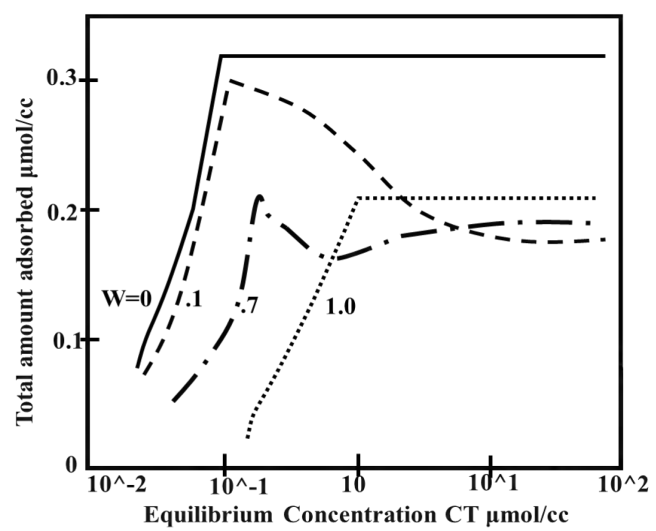

Figure 7 Concentration effect in adsorption isotherm [39]

When surfactant molecules pack together at an interface to form a monolayer, they do no act independently. Molecules interact with neighboring molecules. Interaction between adjacent molecules adsorbed on solid surfaces results in the formation of two-dimensional and eventually three-dimensional active aggregates as the concentration of surfactant solution, from which adsorption takes place, increases [40].

Hanna \& Somasundaran found that on mineral bed, surfactant was adhered as particulate forms and precipitate, this allowed identifying that surfactant trapped was considerably greater than quantity supposed to exist only by adsorption phenomenon. Authors referred to these total losses as adsorption-abstraction process, where both adsorption and precipitation phenomena on a mineral were observed [28]. Adsorption-abstraction is calculated from difference between initial and final sulfonate concentration. At low surfactant concentration, the abstraction amount increases rapidly with concentration until CMC is reached. Each abstraction isotherm depends on kind surfactant used, rock morphological and mineralogical characteristics and electrolytes group present in solution [41].

\section{Adsorption and temperature}

Novosad et al., conducted an experiment aimed at evaluating surfactant solution adsorption into a brine-saturated, unconsolidated sand core. Two specific surfactants were used in the experiment. Their selection was based on tensoactive stability at high temperatures.
Enordet AOS 1,618 with 29.4\% active alpha olefin sulfonate of 356 average molecular weight and Suntech IV with $35 \%$ active synthetic alkyl toluene sulfonate of 418 average molecular weight were surfactants used on the process. In Figure 8, it is shown that there is a decrease in alpha olefin sulfonate and alkyl aryl sulfonate maximum adsorption with a temperature increases from $50^{\circ} \mathrm{C}$ to $150^{\circ} \mathrm{C}$. The sharp reduction in surfactant adsorption

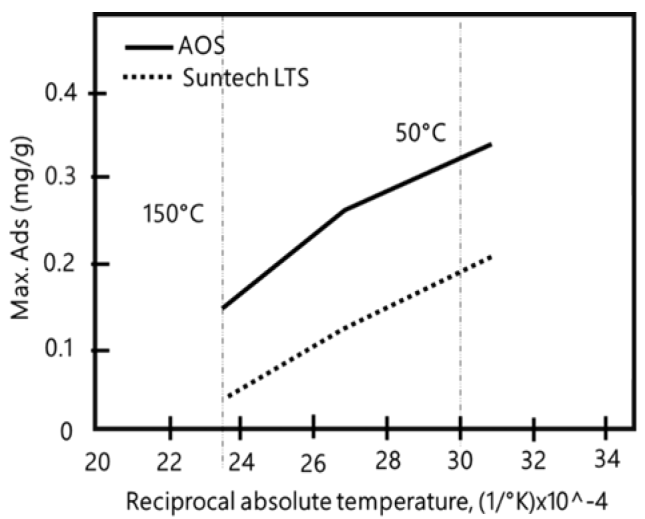

Figure 8 Adsorption evaluation for AOS and AAS surfactants at high temperatures [42]

with increasing temperatures makes field applications of these surfactants for mobility control in steam-floods more attractive [42]. Temperature influences adsorption since reactions are normally exothermic, therefore, this phenomenon will be greater when temperature decreases, although temperature variations have only small changes in adsorption.

Tests were carried out on both surfactants without regard salinity effects. There is an approximately double reduction in adsorption phenomenon by increasing temperature $100^{\circ} \mathrm{C}$ [42]. Foaming-agent loss at the beginning of the process could be reduced because of surfactant contact with steam process temperature. Therefore, it is important to highlight that foam will be able to generate and keep stability while steam occupies spaces that are not part of the preferential flow areas (mobility reduction). Steam zone is where mobility control is most important, adsorption losses will become more severe in the hot water zone where temperature has decreased [42].

Additionally, it is necessary to consider surfactant stability when surfactant is subjected to a representative temperature for a long period of time at different concentrations. As reported by Al-Khafaji et al., displacement experiments were carried out to evaluate adsorption in Ottawa silica sand mixed with kaolinite powder at $205^{\circ} \mathrm{C}$ and $2 \mathrm{MPa}$ conditions. Surfactant known as Suntech IV was used and some results are shown in Table 1. The adsorption test was performed by the 
authors on different representative concentrations. It was observed that the higher the surfactant concentration, the higher surfactant loss. However, most of the material, approximately $90 \%$, remains part of the solution that continues to function as a foaming-agent at high temperature conditions.

Table 1 Suntech IV adsorption evaluation at different concentrations [28]

\begin{tabular}{lll}
\hline \multicolumn{3}{c}{ Adsorption } \\
\hline Solution concentration & Day 1 Wt\% & Day 20 Wt\% \\
\hline $1 \%$ & 0.96 & 0.97 \\
$2 \%$ & 1.92 & 1.79 \\
$5 \%$ & 4.92 & 4.62 \\
\hline
\end{tabular}

\section{Adsorption and salinity}

Salinity is an important factor to consider because of brine presence in porous media. Usually, anionic surfactants are strongly influenced by adsorption on rock surface due to the presence of salt and divalent cations [43]. However, adsorption caused by salinity strongly depends on surfactant molecular structure. For that reason, some types of surfactants can be stable at high salinity and temperature conditions. Coming back to Novosad et al. studies, Table 2 shows some results of adsorption at different sodium chloride $(\mathrm{NaCl})$ concentrations. $\mathrm{NaCl}$ is the most common salt in reservoir brines [44]. Adsorption values in alpha olefin sulfonates were not representative. It can be observed a non-significant change on adsorption value when $\mathrm{NaCl}$ concentration increases to $2 \%$. Nonetheless, alkyl aryl sulfonate adsorption amount showed a significant increase in adsorption phenomenon at only $1 \% \mathrm{NaCl}$ concentration in solution.

Table 2 AOS and AAS adsorption evaluation at different salinity concentrations [42]

\begin{tabular}{cccc}
\hline \multicolumn{4}{c}{ Maximum adsorption $(\mathbf{m g} / \mathbf{g})$ a $\mathbf{5 0 ^ { \circ }} \mathbf{C}$} \\
\hline \multirow{2}{*}{ Surfactant } & Water & $\mathbf{1 \%}$ & $\mathbf{2 \%}$ \\
& & $\mathbf{N a C l}$ & $\mathbf{N a C l}$ \\
\hline Enordet AOS 1618 & 0.2 & - & 0.21 \\
Suntech IV & 0.33 & 0.39 & - \\
\hline
\end{tabular}

Baviere et al. presented some test results that show how alpha olefin sulfonate behavior is at high temperatures and salinities. Adsorption displacement experiments were evaluated between $0.06 \%$ to $8 \% \mathrm{NaCl}$ concentrations. They found that AOS adsorption isotherms remain without a significant change while salinity concentration increases. Other study is on the results reported by Bavière et al. 1991, where AOS adsorption were evaluated on kaolinite with two types of salinity, $\mathrm{NaCl}$ brine and a solution containing calcium and magnesium ions in addition to sodium ions. Once again adsorption shows just a moderate increase because salinity concentration. Therefore, AOS have a molecular structure suitable to support saline environments over a wide range of temperatures [42, 45, 46]. Adsorption phenomenon for AOS at representative salinity concentration will not be representative enough to harm foaming-agent in porous media.

Besides, due to the fact related with previous AAS adsorption results at high salinity conditions, the issue should be studied further. Al-Khafaji et al, included on their adsorption displacement tests, Suntech IV adsorption change analysis due to temperature and salinity concentration effects. It is shown in Table 3. Results proved that salinities greater than $1 \% \mathrm{NaCl}$ concentration will cause large AAS losses because of tensoactive precipitation as suspended gel. AAS surfactant concentration decreases from $1 \%$ to $0.24 \%$ at $2 \% \mathrm{NaCl}$. At $4 \%$, concentration decreased further to $0.00039 \%$. Precipitation can be attributed to material loss as result of abstraction-absorption phenomenon [28]. High salinities in brines at $205^{\circ} \mathrm{C}$ do not represent any beneficial effect. Then, it is important to know reservoir salinity for surfactant selection and to avoid any future complication. Besides, adsorption inhibitors could allow achieving good performances with a properly designed formulation [47].

Table 3 Suntech IV adsorption evaluation at different salinities

[28]

\begin{tabular}{ccc}
\hline \multicolumn{3}{c}{ Suntech IV at $\mathbf{2 0 5}^{\circ} \mathbf{C}$ after $\mathbf{6}$ days } \\
\hline $\begin{array}{c}\text { NaCl } \\
\text { content }\end{array}$ & $\begin{array}{l}\text { Concentration } \\
\text { w*\% by } \\
\text { weight }\end{array}$ & $\begin{array}{l}\text { Concentration } \\
\mathbf{w} * \% \text { by weight, } \\
\text { Adsorption }\end{array}$ \\
\hline Suntech IV pure & 1.022 & - \\
$0.25 \%$ & 1.015 & 0.984 \\
$0.50 \%$ & 1.013 & 0.984 \\
$1 \%$ & 1.008 & 0.981 \\
$2 \%$ & 0.24 & 0.066 \\
$4 \%$ & 0.038 & 0.008 \\
\hline
\end{tabular}

\section{Adsorption and clay presence}

Investigating adsorption of surfactants to rocks that vary in their lithological characteristics is a prerequisite for assessing an EOR process [48]. Despite anionic and sandstones rejection charges, clay presence in this formation could increase surfactant adsorption. Some clay minerals found on conventional reservoirs are mainly kaolinite and montmorillonite [49]. However, there is a principal difference between these two types of clay, kaolinite non-swelling and montmorillonite swelling 
at water contact [50]. Keeping in mind the Langmuir model, contact area has a representative role in terms of adsorption. Adsorption could increase because of contact area incrementation and ionic interactions that may occur in porous medium, derived from clay contact with surfactant.

Clay presence is a parameter considered on adsorption experiments developed by Amirianshoja et al. Quartz sand and clay mineral were mixed with anionic surfactant and then with non-ionic surfactant. After, they were separated by centrifugation to calculate adsorption values from the difference of the CMC before and after adsorption. Adsorption of the anionic surfactant was negligible and adsorption power of clay mineral are montmorillonite $>$ kaolinite [48]. Other example is also developed by Novosad et al., studies. Some results of foaming-agent AOS displacement through cores with clay presence are displayed in Table 4. For montmorillonite adsorption corresponds to $0.08 \mathrm{mg} / \mathrm{g}$ which is approximately $40 \%$ of the initial loss. On the other hand, kaolinite clay only increased adsorption at $0.02 \mathrm{mg} / \mathrm{g}$ which refers to $10 \%$ of initial value [42]

Table 4 Enordet AOS 16-18 adsorption evaluation in the presence of clay [42]

\begin{tabular}{llll}
\hline Clay & Clay \% & $\begin{array}{l}\text { Adsorption } \\
\text { (mg/g) }\end{array}$ & $\begin{array}{l}\text { Adsorption } \\
\text { without } \\
\text { clay (mg/g) }\end{array}$ \\
\hline $\begin{array}{l}\text { Montmori- } \\
\text { llonite }\end{array}$ & 10 & 0.28 & 0.20 \\
Kaolinite & 10 & 0.22 & 0.20 \\
\hline
\end{tabular}

The type of clay minerals will determine the efficiency of an anionic foaming-agent in steam processes [51]. Interaction between solution and clays causes tensoactive loss that could rely on contact area increasing and chemical nature of minerals, where anionic surfactants showed better behavior. For montmorillonite, its swelling nature and water contained on surfactant solution contact could make rock matrix with a greater surface area, so adsorption is greater than shown by the Kaolinite. Therefore, clay in reservoir should be classified and amount should be estimated to relate foaming agent with possible future adsorption losses.

\subsection{Phase partitioning}

Phase partitioning has been an important subject for experimentation and study for many years [25]. It refers to surfactant affinity for either water or oil underpins [35]. This phenomenon tries to quantify selective dissolution between two immiscible solvents phases where because of extraction process a substance is separated from the center of mixture, by solvent action that dissolves it selectively [28], as can be seen in Figure 9.

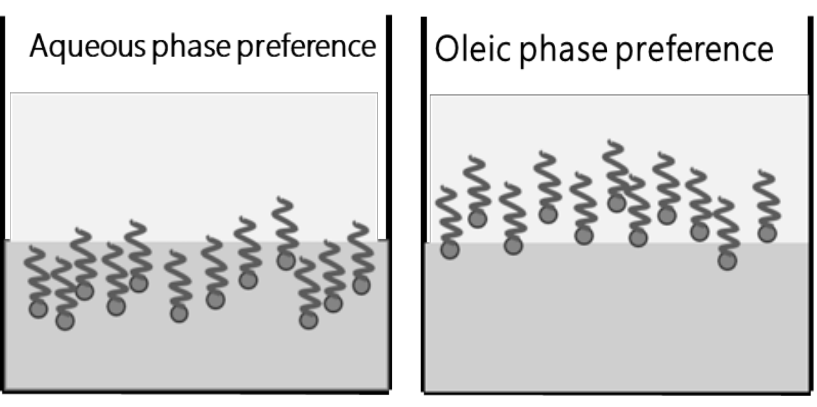

Figure 9 Schematic representation of surfactant partitioning in a solution

Surfactant solution injected into reservoir can be considered as a three elements system composed of brine, surfactant, and oil, each of these components rely on variable that interact with tensoactive structure and final behavior. Substances equilibrium properties can be represented in a ternary diagram, as shown in Figure 10. On a ternary diagram, a binodal curve describes a boundary between a single-phase (top region) and a multiphase section (bottom region). Micro-emulsion or micellar fluid are represented by single-phase section and two or more phases in equilibrium are represented by multiphase region. Miscible local displacement is favored for ternary diagram with a single-phase region as large as possible [28]. A multiphase region in a ternary diagram involves two external phases, oil and water, which are at opposite ends of lower vertices and an intermediate lamella structure phase, in which there may be a gel or a liquid crystal, these three types of micelles can coexist in equilibrium even when they constitute separate immiscible phases [35, 52-54].

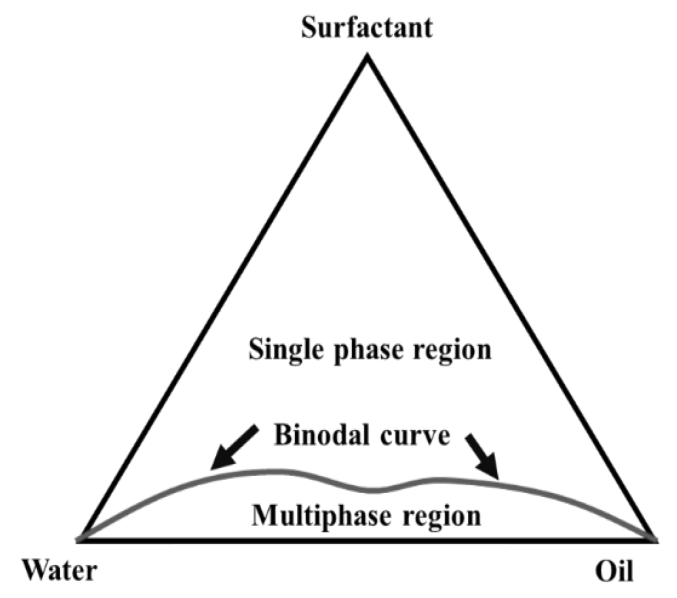

Figure 10 Schematic ternary diagram for partition phenomenon [28]

The most general approach to distribution phenomena is to treat the Partition law as an extension of Henry's law 
[25]. Whether in a system of two immiscible or very low miscible liquid phases known as $A$ and $B$, where a third component $Z$ is added and is soluble in both phases, it will be distributed in each liquid phases in such a way that coefficient resulting from dividing concentration in each phase will be a constant that will only depend on temperature [54].

The partition coefficient described in Equation 2, indicates hydrophilic or hydrophobic character of a substance. Surfactant preference to dissolve in polar solvents or in organic solvents. CA and CB refer to surfactant concentration in oleic phase and surfactant concentration in aqueous phase respectively [22]. The value of the coefficient will allow analyzing surfactant preference. If partitioning coefficient is greater than 1, surfactant prefers oleic phase solution, and when it is less than 1, surfactant preference is in aqueous phase.

$$
K p=\frac{(C A)}{(C B)}
$$

On the other hand, there is a methodology widely used in petroleum industry to measure surfactant solution partitioning in reservoir known as hydrophilic-lipophilic balance $(H L B)$. The $H L B$ value represents the relative tendency of a surfactant molecule to transfer from an aqueous to a hydrocarbon environment and vice versa, mainly non-ionic tensoactives or surfactant mixtures [55]. $H L B$ could be directly related to the partition coefficient which is based firmly on thermodynamics to obtain better approaches of partitioning effect [25]. It is represented in Equation 3.

$$
(H L B-7)=0.36 L N \frac{1}{K p}
$$

While Partition coefficient is based on concentration comparison of solute between these two liquid phases, $H L B$ refers to hydrophilic or lipophilic preference, determined by calculating values for the different regions of the molecule (Empirical Method) [56]. If a surfactant has an $H L B=1$, it is oil soluble, while a surfactant with an $H L B=15$ is water soluble [55]. Generally, surfactant with high $H L B$ value $(H L B>13$ ) is considered to impart good foaming behavior [57].

$K p$ and $H L B$ number are important criteria to quantify surfactant loss caused by partitioning effects at reservoir conditions. The main parameters that affect surfactant partitioning in porous medium are surfactant concentration, salinity, oil chain length and temperature [58]. Therefore, surfactant selection could be improved by partition coefficient and $H L B$ evaluation considering reservoir parameters through partitioning experiments. Partitioning test consists of putting crude oil and surfactant solution in contact for a specific period under different conditions (pressure and temperature). Then, surfactant initial solution concentration is compared with the resultant concentration in aqueous phase at the end of the experiment [28].

\section{Phase partitioning and concentration}

The Concentration is the main parameter to quantify phase partitioning between oil and water. Identifying concentration effect on surfactant solution will display how $K p$ behaves as anionic surfactant concentration increases. Figure 11 shows some results obtained by Al-Khafaji et al. They evaluated $K p$ behavior of alkyl aryl sulfonate Suntech IV while concentration increases in partitioning experiments after two days at $205^{\circ} \mathrm{C}$. It can be observed that partition coefficient acquires high values at low concentrations, maximum $K p$ in the figure is on $0.25 \%$ w. However, $K p$ value decreases to small values as the surfactant concentrations increases. Tensoactive percentage that remains in aqueous phase and usable for subsequent parts of the process does not decrease less than $60 \%$ [28].

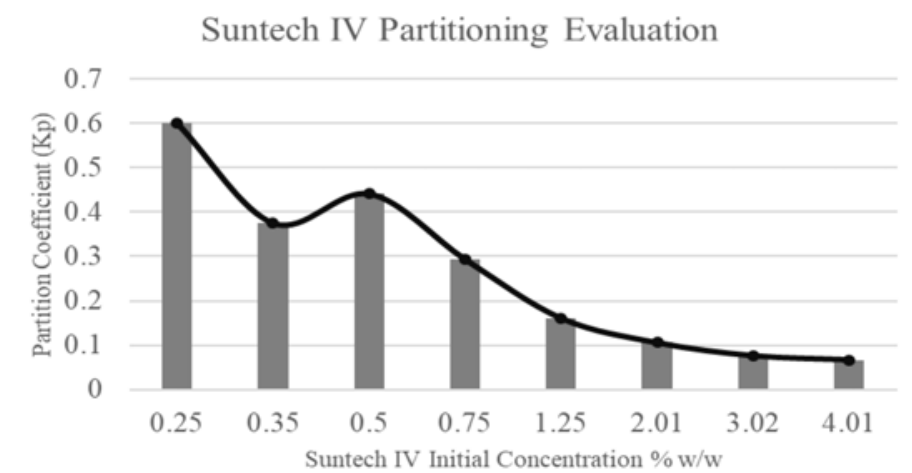

Figure $11 \mathrm{Kp}$ of Suntech IV at different concentrations [28]

The same procedure was done by Belhaj et al. Phase partitioning behavior because of concentration variation for nonionic surfactant Alkyl poly glucoside (APG) was evaluated at $80^{\circ} \mathrm{C}$. They found different behaviors before and after $\mathrm{CMC}$ was reached. For pre-CMC, partitioning coefficient constantly increase until reach a maximum $K p$ value at $0.2 \%$ w concentration. Maximum $K p$ means high partitioning and is related with minimum interfacial tension (IFT) value. This is due to the presence of available surface space of oil to cover by surfactant molecules resulting in IFT low values. For post-CMC, $K p$ value tends to decrease after surfactant maximum concentration was reached. $K p$ values at higher concentrations were low because of micelles stop increasing causing a lower partitioning rate of the surfactant molecules into the water-oil interface [59-61].

$K p$ values demonstrate once again the importance 
of the initial concentration selection of foaming agent in steam processes. It is necessary to consider CMC of the tensoactive solution; this is because the principal goal is surfactant stability maintaining it in aqueous phase for subsequent foam generation. Partitioning experiments allowed defining that at lower initial concentrations, surfactant loss will be considerable because of molecules placement in oil. Therefore, an initial concentration should be selected contemplating possible initial surfactant loss and foam stability.

\section{Phase partitioning and temperature}

For temperature effect evaluation in phase partitioning, it is necessary to calculate $K p$ coefficient considering concentrations measurements before and after each experiment. Al-Khafaji et al. also developed partitioning evaluation. Partitioning experiment data was obtained evaluating alkyl toluene sulfonate surfactant known as Suntech IV over the days, at $205^{\circ} \mathrm{C}$ and $2 \mathrm{MPa}$, it is shown in Table 5. The main goal was to identify surfactant loss tendency because of its retention in oleic phase [28]. It can be observed and abrupt surfactant loss at the beginning of the test, then $K p$ coefficient tends to a constant value. After 20 days of being exposed to about $205^{\circ} \mathrm{C}$ no more losses were registered by the authors.

Table 5 Suntech IV partitioning through time [28]

\begin{tabular}{ccc}
\hline \multicolumn{3}{c}{ Partitioning test } \\
\hline \multicolumn{3}{c}{ Solution of 2\% weight percentage } \\
\hline Time interval & Conc. Wt\% & Kp \\
Fresh sample & 2 & 0 \\
First day & 1.42 & 0.41 \\
Sixth day & 1.37 & 0.44 \\
Twelfth day & 1.34 & 0.49 \\
\hline
\end{tabular}

Furthermore, based on information by Belhaj et al. They also evaluated phase partitioning behavior of anionic tensoactive, after one day of exposure, known as alkyl ether carboxylate (AEC) with some initial surfactant concentrations at different brine/oil ratios, high temperatures and atmospheric pressure, one example is shown in Figure 12. $K p$ values for all scenarios were higher at $106^{\circ} \mathrm{C}$ as compared with $80^{\circ} \mathrm{C}$ after one day of exposure [62].

High temperatures increase solubility of the surfactants hydrophobic tail in the water and move the surfactant to the oil-water interface causing a reduction in IFT $[59,63]$. Besides, high temperature makes easier for surfactant enter to the oil phase, because of oil viscosity reduction [62]. According to the above data criteria obtained by the authors, substantial foaming-agent loss was observed at the beginning of each experiment and partition coefficient

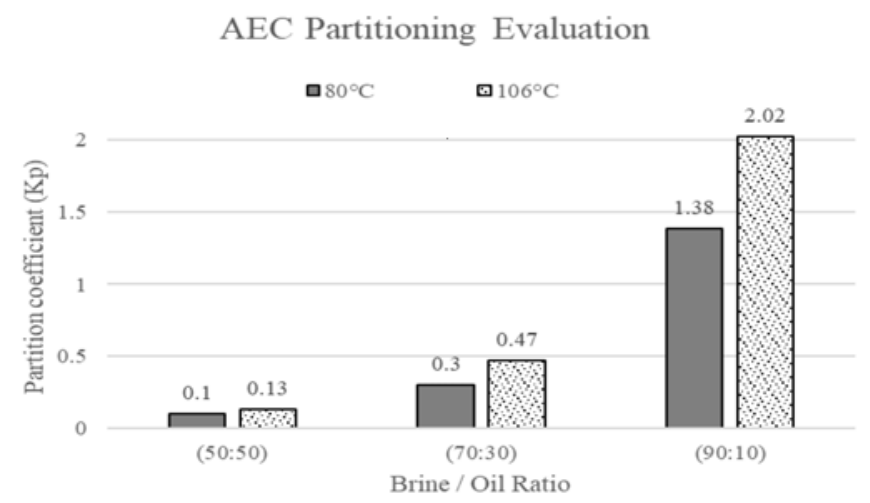

Figure $12 \mathrm{Kp}$ of APG with initial surfactant concentration 0.3 $w t \%$ at different brine/oil ratios and high temperatures [62]

tends to increase its value as temperature increases. However, there is another parameter that produces significant changes on partition coefficient, which is salinity, this effect should also be considered for phase partition.

\section{Phase partitioning and salinity}

Chan \& Shah identified that as salinity ( $\mathrm{NaCl}$ concentration) increases, the surfactant molecules will partition preferentially in the oleic phase until reaching a phase inversion point. $K p$ value is one at the phase inversion salinity point [58]. Phase inversion on a petroleum sulfonate can be observed in Figure 13. At the initial surfactant concentration, the tensoactive tends to prefer aqueous phase. This tendency remains until reaching a $3 \%$ $\mathrm{NaCl}$ concentration. Then, surfactant amount that tends to prefer oleic phase begins to increase until reaching a point of phase inversion where surfactant will prefer oleic phase.

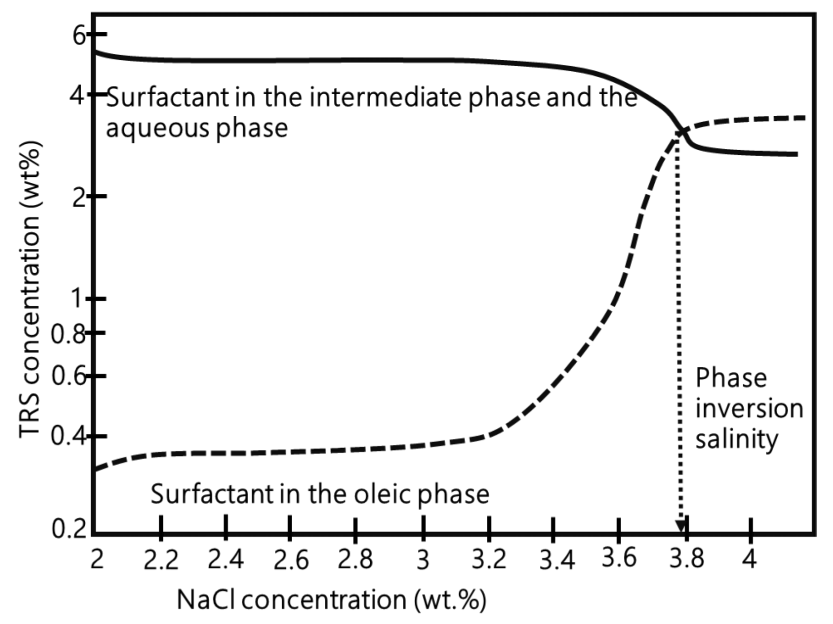

Figure 13 Petroleum sulfonate partition at high salinity concentration [58] 
For experiments developed by Al-Khafaji et al. phase partition of alkyl aryl sulfonate known as Suntech IV was tested at different salinities and $205^{\circ} \mathrm{C}$. It was found that at low concentrations of $\mathrm{NaCl}$, less than $1 \% \mathrm{w}$, surfactant partitioning showed a non-representative initial loss. However, the tensoactive precipitated as suspended gel at higher salinities [28]. This is a clear proof that salinity should be considered when a surfactant solution is chosen to design a foaming agent.

Another example is also found on Belhaj et al. studies. They tested the partitioning of alkyl ether carboxylate between $0 \%$ to $3.2 \%$ of $\mathrm{NaCl}$ concentration. Phase partition showed an increase because of salinity. Nonetheless, $K p$ value increasing was slower as compared with temperature effect. Some results obtained by the authors are displayed in Figure 14. Salinity in an anionic surfactant solution promotes changes in the phase behavior from lower phase laqueous section), through middle phase toward upper phase (oleic section). Middle phase shows low interfacial tensions against oil and water. Thus, there is a partitioning into the interface and a reduction on IFT values due to the decrease in the repulsive forces caused by the presence of monovalent and divalent ions from the salt. $[58,62,64]$.

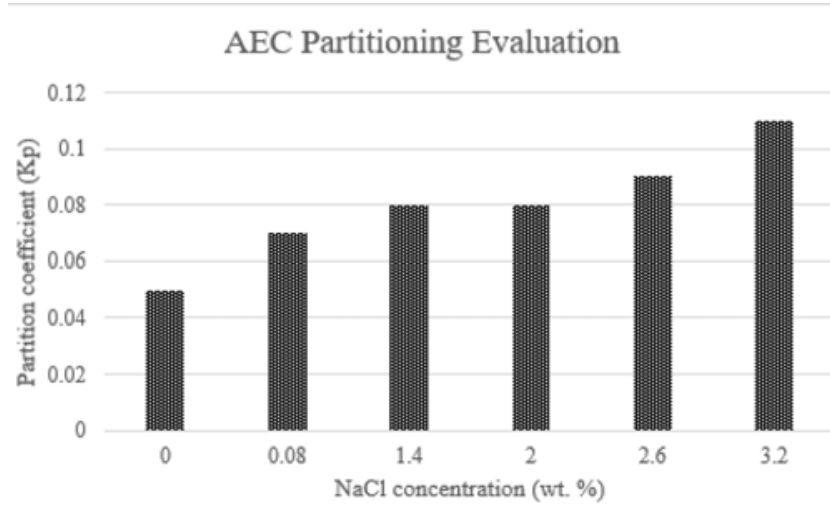

Figure $14 \mathrm{Kp}$ of $\mathrm{AEC}$ with initial surfactant concentration 0.4 wt $\%$ at different salinities and $106^{\circ} \mathrm{C}$ of temperature [62]

\section{Phase partitioning and carbon chain length}

$H L B$ value is considered an empirical way to determine surfactant molecule preference to aqueous phase or oleic phase. Equation 3 is a method to calculate $H L B$ based on partition coefficient experimental data obtained However, there are more equations developed and related specifically to non-ionic surfactants [65]. Graciaa et al. calculated $H L B$ values of non-ionic surfactant known as Ethoxylate Octyl Phenols at $25^{\circ} \mathrm{C}$, as it is shown in Figure 15. $K p$ values indicated that the surfactant molecules have a greater affinity for the oil than for the water when surfactant chain length is less than $\mathrm{C} 8$ and $H L B$ values are greater than 13 [66].

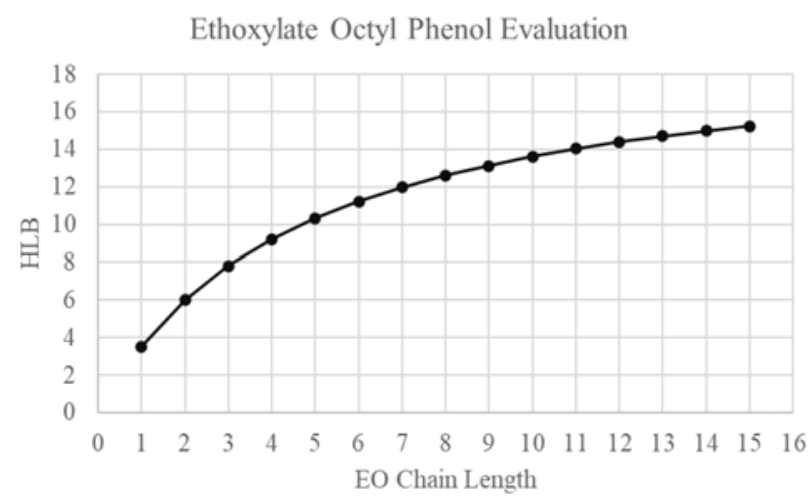

Figure 15 Relationship evaluation between $\mathrm{HBL}$ and the chain length of the surfactant EO [66]

Chan \& Shah identified that surfactant is preferentially soluble in oil phase if the sulfonates are of shorter chain length, and in brine phase if the longer chain length oils are used. They evaluated petroleum sulfonates anionic surfactants systems of various chain length from $\mathrm{C} 6$ to C16 known as TRS, with an initial concentration of $5 \%$ in $1.5 \% \mathrm{NaCl}$ brine equilibrated. Surfactant molecules partitioned in oil phase and located in oil-external section at oil chain length less than $\mathrm{C} 10$. For oil chain length range between $\mathrm{C} 11$ to $\mathrm{C} 14$, surfactant located in middle-phase. Thus, water-external microemulsion was observed at chain length greater than $\mathrm{C} 15$. They could also define that partition coefficient value is unity at C12 oil chain length [58].

Foaming agent stability is affected by chain length of the surfactant molecule. This can be observed in the calculation of $H L B$ number and the changes in the partition coefficient. Considering the experimental tests developed by the author mentioned above, it can be specified that a surfactant will remain in the aqueous phase when the $H L B$ value is greater than 13 and $K p$ value is less than 1 . These criteria are accomplished when carbon chain length of surfactant is greater than C12 $[58,65,66]$. Hydrocarbon chain length can be the major determining factor for the $K p$ of ionic surfactants. However, it is necessary to consider other structural parameters in the molecules [55]. Some examples of structural parameters were previously mentioned and correspond to molecular arrangement and polar group.

\subsection{Thermal Degradation}

Thermal degradation refers to surfactant stability under steam injection processes conditions. Degradation phenomenon can be greatly mitigated through selection and correct design of tensoactive that will form foaming agent. This process takes place in certain substances 
when they are exposed to high temperatures. Surfactant structure loses its initial design and could affect the foam generation. To understand this process, it is necessary to consider its thermal kinetics decomposition.

Tensoactives are organic compounds and tend to be affected by thermal degradation. Depending on temperature at which they are exposed, they can suffer chemical reaction [28]. As mentioned above, sulfonate surfactants have shown stability at high temperatures. Therefore, it is important to identify the possible thermal reaction kinetics that can take place in porous medium due to high temperatures conditions.

Handy et al. developed experiments to evaluate half-life of petroleum sulfonates during 11 days at $180^{\circ} \mathrm{C}$. Based on authors results, surfactant decompose following first order kinetics. The reaction that explains surfactant decomposition along tests is shown below [67].

$$
\mathrm{ArSO}_{3}{ }^{-}+\mathrm{H}_{2} \mathrm{O} \quad-\mathrm{K} \rightarrow \mathrm{ArH}+\mathrm{SO}_{4}^{2-}+\mathrm{H}^{+}
$$

For each decomposed sulfonate molecule, a hydrogen ion is produced. It can be monitored by $\mathrm{pH}$ measuring of solution. Reagent $\left[\mathrm{ArSO}^{3-}\right.$ ] refers to sulfonate concentration at time $t$.

On the other hand, Angstadt and Tsao, evaluated the kinetics of the decomposition of some alkyl aryl sulfonates and alpha olefin sulfonates under controlled temperature conditions. Component changes of surfactant were measured by high-performance liquid chromatography (HPLC) and two-phase titration. After solution exposure to temperatures up to $300^{\circ} \mathrm{C}$ for two days, the autocatalytic model of acid catalysis shown below were related with the experiment results. This reaction shows an electrophilic attack on the aromatic portion of the molecule [68].

$$
\begin{aligned}
\mathrm{ArSO}_{3}^{-}+\mathrm{H}_{3} \mathrm{O}^{+}-\mathrm{K} & \rightarrow \mathrm{ArH}+\mathrm{HSO}_{4}^{-}+\mathrm{H}^{+} \\
\mathrm{HSO}_{4}^{-}-\mathrm{K} & \rightarrow \mathrm{SO}_{4}^{2-}+\mathrm{H}^{+}
\end{aligned}
$$

Then,

$$
\mathrm{ArSO}_{3}^{-}+\mathrm{H}_{3} \mathrm{O}^{+} \quad-\mathrm{K} \rightarrow \mathrm{ArH}+\mathrm{SO}_{4}^{2-}+2 \mathrm{H}^{+}
$$

Sulfonates surfactants degradation could be modeled using first-order reactions models. Experiments results showed by several authors conclude that the best description of thermal degradation is obtained with a first order reaction model [28, 67-69].

According to Maini and Ma experiments carried out to evaluate thermal degradation and foam stability. AOS sulfonates concentration was measured at different temperatures and 6.9 MPa of pressure, using two-phase titration method. In Figure 16, it is shown surfactant stability at $200^{\circ} \mathrm{C}$ with a $\mathrm{pH}$ adjustment done by addition of potassium hydroxide $(\mathrm{KOH})$. C/Co corresponds to the relation between concentration at time $\mathrm{t}$ and initial concentration. For AOS with a chain length between $\mathrm{C} 14$ to $\mathrm{C} 24$, it was not registered concentration representative changes as it was for AOS C24-28. Authors also defined that temperatures above $200^{\circ} \mathrm{C}$ were not recommended because of surfactant degradation [18].

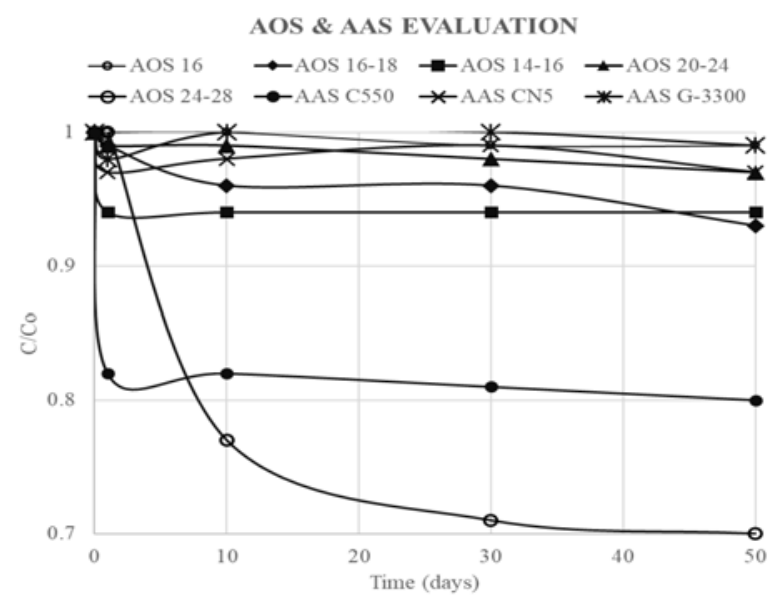

Figure 16 Thermal degradation of AOS and AAS of different chain length at $200^{\circ} \mathrm{C}$ and $6.9 \mathrm{MPa}$ [18]

In Figure 16, some results of thermal degradation for some AAS without $\mathrm{pH}$ adjustment are also shown. These surfactants remain stable, even without $\mathrm{KOH}$ addition. Two AAS that remained with $C$ / Co greater than 0.95 , could be used up to temperatures of $300^{\circ} \mathrm{C}$ [18]. Sulfonate stability of Suntech IV were also tested by Al-Khafaji et al. It was found that thermal degradation of AAS is not representative at $205^{\circ} \mathrm{C}$ [28].

Thermal tensoactive loss, due to chemical kinetic reactions, is not representative as loss that is generated by phenomena such as adsorption and partitioning. It could be defined that sulfonates are considered in steam-foam injection processes because of their high stability and foaming generation ability. AAS have shown to be more resistant than AAS and petroleum sulfonates at alkaline conditions and temperatures up to $300^{\circ} \mathrm{C}$ [69]. However, AOS are stable to be used as a foaming agent in steam floods [18]. A way to reduce surfactant loss in reservoir by thermal degradation is by selecting and designing surfactant solution. Correct chain length and appropriate $\mathrm{pH}$ could improve foaming stability in porous medium.

Finally, in Figure 17, the representative phenomena that could affect surfactant agent in steam-foam injection processes is shown. This figure shows a summary of the concentration change of surfactant known as Suntech IV because of loss phenomena along days at $205^{\circ} \mathrm{C}$. Considering the authors studies cited above, it is possible to identify that phase partitioning could cause 
higher tensoactive loss. An initial foaming agent loss occurs at the first contact with oil phase. In the case of adsorption, the tensoactive loss trend is comparable to a straight line with a gentle slope. Thermal degradation is highly mitigated by selection of resistant agents to high temperatures, for this reason its effect is not representative as the other phenomena. However, for the designing of a foaming agent solution is necessary to consider the sum of all effects to define the stability of the surfactant during the process. This is directed toward achieving the main goal of maintaining agent integrity to foam generation and steam redirection to other sections of the reservoir.

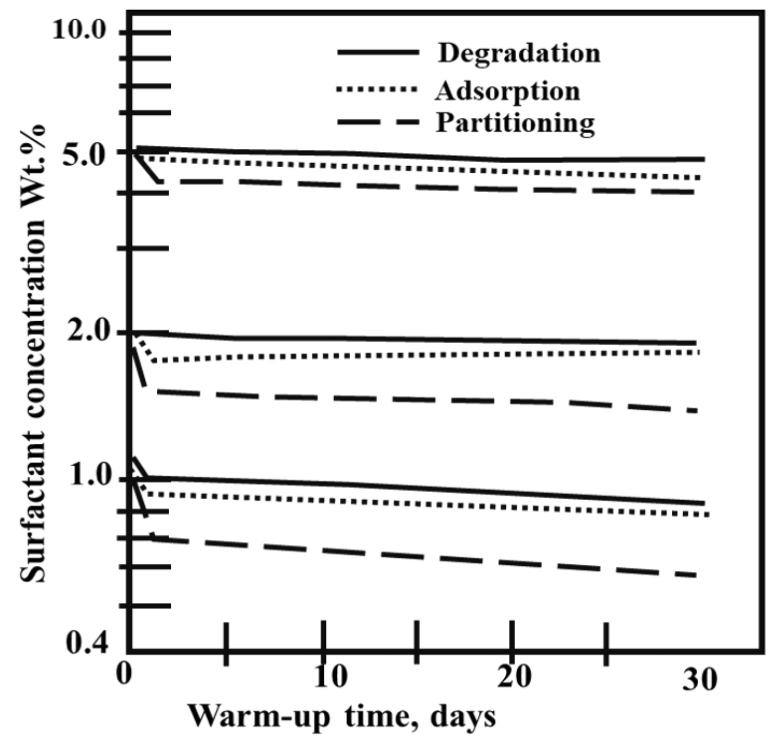

Figure 17 Degradation, adsorption, and partitioning phenomena of surfactant Suntech IV [28]

\section{Conclusions}

Steam-foam processes require the correct selection of a surfactant agent resistant to high temperatures, stable over time and with representative reduction mobility of the steam. State of the art revision allows identifying some types of sulfonates that are characterized by being molecularly suitable for steam procedures because of its anionic nature, long linear chain length and polar group head. The types of sulfonates are alkyl aryl sulfonates and alpha olefin sulfonates.

The main phenomena that could cause surfactant loss in porous medium are phase partitioning, adsorption, and thermal degradation; phase partitioning could cause higher tensoactive loss. Adsorption on the solid phase and phase partitioning in the oleic phase have a direct relationship with the surfactant concentration below its critical micellar concentration since surfactant loss is significant until reaching $\mathrm{CMC}$, then the adsorption value tends to be constant and $K_{p}$ coefficient value decreases sharply away from the unity which means preference to the aqueous phase.

Reservoir conditions such as temperature, salinity and presence of clay are parameters that influence surfactant solution behavior.

High temperatures in porous medium could reduce tensoactive loss by adsorption due to exothermic reactions. However, foaming agents could be partitioned into oleic phase owing to viscosity reduction and molecules motion improvement towards crude oil.

High concentrations of salinity in the brine could produce some side effects. Some examples are an increase in adsorption measurements, surfactant preference to oil due to phase inversion or even surfactant precipitation because of agent molecular low resistance to saline environments.

Clay presence is directly related with adsorption measurements. Swelling clays as montmorillonite increase adsorption onto solid phase, this could be explained by the maximization in contact surface area between agent solution and rock matrix.

Surfactant solution should be formed by a mixture of components that provides stability during the steam injection process. Generally, the solution is composed mainly of an anionic surfactant. In the case of alkyl aryl sulfonates, these are suitable for high temperatures up to $300^{\circ} \mathrm{C}$, although they have low stability to high salinity situation. On the contrary Alpha olefin sulfonates possess high resistance to salinity, despite their thermal stability is up to $200^{\circ} \mathrm{C}$. However, other anionic surfactants have shown promising results to high temperature conditions as alky ether carboxylate and petroleum sulfonates. Besides, non-ionic surfactants and $\mathrm{pH}$ adjustment substances could be added to give foaming agent an improved performance.

\section{Declaration of competing interest}

We declare that we have no significant competing interests including financial or non-financial, professional, or personal interests interfering with the full and objective presentation of the work described in this manuscript.

\section{Acknowledgements}

This study has been developed as a line of Research Group GRM at Universidad Industrial de Santander. 


\section{References}

[1] K. Delac and M. Grgic, "Updated screening criteria for steam injection projects based on oil worldwide survey," in $2^{\text {nd }}$ Conference for Engineering Sciences and Technology - CEST2 29-31, Sabratha, Libya, 2019, pp. 1-12.

[2] S. Paria and K. C. Khilar, "A review on experimental studies of surfactant adsorption at the hydrophilic solid - water interface," Advances in Colloid and Interface Science, vol. 110, no. 3, August 31 2004. [Online]. Available: https://doi.org/10.1016/j.cis.2004.03.001

[3] A. M. Venera, M. C. Ariza, A. X. Rodriguez, and S. F. Muñoz, "Técnicas para el mejoramiento de la inyección continua de vapor," Revista Fuentes: El Reventón Energético, vol. 15, no. 1, 2017. [Online]. Available: https://doi.org/10.18273/revfue.v15n1-2017010

[4] G. Hirasaki, "The steam-foam process," Journal of Petroleum Technology, vol. 41, no. 5, May 1989. [Online]. Available: https: //doi.org/10.2118/6845-PA

[5] S. Thomas, "Enhanced oil recovery - An overview," Oil \& Gas Science and Technology, vol. 63, no. 1, January 2007. [Online]. Available: https://doi.org/10.2516/ogst:2007060

[6] M. J. Rosen and M. Dahanayake, Industrial utilization of surfactants: Principles and practice, 1st ed. USA: Amer Oil Chemists Society, 2000.

[7] J. J. Sheng, Modern Chemical Enhanced Oil Recovery. Theory and Practice, 1st ed. Burlington, USA: Gulf Professional Publishing, 2010.

[8] R. L. Horton, J. P. Wicks, J. Prieditis, and J. B. Turbeville, "An objective rapid screening tool for surfactants used in foam-like dispersions of $\mathrm{CO} 2$ into permian basin brines," in SPE International Symposium on Oilfield Chemistry, San Antonio, Texas, 1995.

[9] D. Wasan and V. Mohan, "Interfacial rheological properties of fluid interfaces containing surfactants," in Improved Oil Recovery by Surfactant and Polymer Flooding, D. D. Shah and R. S. Schechter, Eds. Academic Press Inc, 1977, pp. 161-203.

[10] J. K. Borchardt and A. R. Strycker, "Olefin sulfonates for high temperature steam mobility control: structure-property correlations," in International Symposium on Oilfield Chemistry, Houston, Texas, 1997.

[11] H. C. Lau and J. K. Borchardt, "Improved steam foam formulations: concepts and laboratory results," SPE Reservoir Engineering, vol. 6, no. 4, November 1991. [Online]. Available: https://doi.org/10.2118/ 18783-PA

[12] S. R. Grundmann and D. L. Lord, "Foam stimulation," Journal of Petroleum Technology, vol. 35, no. 3, March 1983. [Online]. Available: https://doi.org/10.2118/9754-PA

[13] H. Lashgari, M. Lotfollahi, M. Delshad, K. Seperrnoori, and E. Rouffignac, "Steam-surfactant-foam modeling in heavy oil reservoirs," in SPE Heavy Oil Conference-Canada, Calgary, Alberta, Canada, 2014.

[14] J. Borchardt, D. Bright, M. Dickson, and S. Wellington, "Surfactants for $\mathrm{co}^{2}$ foam flooding," in SPE Annual Technical Conference and Exhibition, Las Vegas, Nevada, 1985.

[15] A. Cuenca, E. Lacombe, M. Chabert, M. Morvan, and E. Delamaide, "Enhanced viscosity formulations for steam foam applications: Impact on performances in bulk and porous media," in SPE Canada Heavy Oil Technical Conference, Calgary, Alberta, Canada, 2015.

[16] H. Lau, "Alkaline steam foam: Concepts and experimental results," in SPE Enhanced Oil Recovery Conference, Kuala Lumpur, Malaysia, 2011.

[17] H. M. Muijs, P. P. Keijzer, and R. Wiersma, "Surfactants for mobility control in high-temperature steam-foam applications," in SPE Enhanced Oil Recovery Symposium, Tulsa, Oklahoma, 1988.

[18] B. B. Maini and V. Ma, "Thermal stability of surfactants for steamflood applications," in SPE Oilfield and Geothermal Chemistry Symposium, Phoenix, Arizona, 1985.

[19] K. Peter and C. Vollhardt, Química orgánica, 1st ed. Barcelona, España: Ediciones Omega S.A., 1994.

[20] M. R. Demiral and E. Okandan, "Experimental analysis of steam foam injection to heavy oil limestone reservoirs," in Middle East Oil
Show, Bahrain, 1987.

[21] H. R. Froning, S. H. Raza, and W. S. Askew, "Method of mobility control in miscible displacement process," U.S. Patent US 3722590 , jun 1, 1971.

[22] G. Hirasaki, C. Miller, and G. Pope, "Surfactant based enhanced oil recovery and foam mobility control," Rice University and The University of Texas, Texas, USA, Tech. Rep. DE-FC26-03NT15406, jul 2005.

[23] A. C. andet al, "Design of thermally stable surfactants formulations for steam foam injection," in SPE Canada Heavy Oil Technical Conference, Calgary, Alberta, Canada, 2014.

[24] P. Moreau, F. Oukhemanou, A. Maldonado, and B. Creton, "Application of quantitative structure-property relationship (QSPR) method for chemical eor surfactant selection," in SPE International Symposium on Oilfield Chemistry, Texas, USA, 2013.

[25] A. Leo, C. Hansch, and D. Elkins, "Partition coefficients and their uses," Chemical Reviews, vol. 71, no. 6, December 1 1971. [Online]. Available: https://doi.org/10.1021/cr60274a001

[26] J. Avendaño, M. Arce, J. L. Salager, and R. Mercado, "Adsorción de surfactantes catiónicos sobre arena en función de la carga superficial del sustrato y la longitud de cadena hidrocarbonada del surfactante," Revista Ciencia e Ingeniería, vol. 30, no. 1, pp. 15-23, 2009.

[27] P. Somasundaran and H. Hanna, "Adsorption of sulfonates on reservoir rocks," Society of Petroleum Engineers Journal, vol. 19, no. 4, August 1979. [Online]. Available: https://doi.org/10.2118/ 7059-PA

[28] A. Al-Khafaji, L. Castanier, and W. Brigham, "Effect of temperature on degradation, adsorption and phase partitioning of surfactants used in steam injection for oil recovery," Stanford University Petroleum Research Institute, Stanford, CA, Tech. Rep., 1984.

[29] S. H. Maron and C. F. Prutton, Principles of Physical Chemestry, 4th ed. USA: Collier Macmillan Ltd, 1965.

[30] D. S. Ballantine and et al, "Materials characterization," in Acoustic Wave Sensors: Theory, Design and Physico-Chemical Applications, D. S. Ballantine and et al, Ed. San Diego, USA: Academic Press, 1997, pp. 150-221.

[31] G. Para, E. Jarek, and P. Warszynski, "The surface tension of aqueous solutions of cetyltrimethylammonium cationic surfactants in presence of chloride and bromide counterions," Colloids and Surfaces A: Physicochemical and Engineering Aspects, vol. 261, no. 1-3, July 2005. [Online]. Available: https://doi.org/10.1016/j. colsurfa.2004.11.044

[32] D. Fuerstenau, "Zeta potentials in the flotation of oxide and silicate minerals," Advances in Colloid and Interface Science, vol. 114-115, June 2005. [Online]. Available: https://doi.org/10.1016/j.cis.2004. 08.006

[33] V. M. Ziegler and L. L. Handy, "Effect of temperature on surfactant adsorption in porous media," Society of Petroleum Engineers Journal, vol. 21, no. 2, April 1981. [Online]. Available: https: //doi.org/10.2118/8264-PA

[34] S. Azizian, S. Eris, and L. D. Wilson, "Re-evaluation of the century-old Langmuir isotherm for modeling adsorption phenomena in solution," Chemical Physics, vol. 513, September 24 2018. [Online]. Available: https://doi.org/10.1016/j.chemphys. 2018.06.022

[35] R. Flatt and I. Schober, "Superplasticizers and the rheology of concrete," in Understanding the rheology of concrete, N. Roussel, Ed. Woodhead Publishing, 2012, pp. 144-208.

[36] A. M. Novelo and J. Gracia, "Concentración micelar crítica mediante la ecuación de adsorción de Gibbs," Educación Química UNAM, vol. 16, no. 1, December 1 2005. [Online]. Available: http: //dx.doi.org/10.22201/fq.18708404e.2005.1.66139

[37] M. Rizwan and et al, "Static adsorption of anionic surfactant onto crushed Berea sandstone," Journal of Petroleum Exploration and Production Technology, vol. 3, September 2003. [Online]. Available: https://doi.org/10.1007/s13202-013-0057-y

[38] S. P. Trushenski, D. L. Dauber, and D. R. Parrish, "Micellar flooding - fluid propagation, interaction, and mobility," Society of Petroleum Engineers Journal, vol. 14, no. 6, December 1974. [Online]. Available: 
https://doi.org/10.2118/4582-PA

[39] F. J. Trogus, R. S. Schechter, G. A. Pope, and W. H. Wade, "Adsorption of mixed surfactant systems," Journal of Petroleum Technology, vol. 31, no. 6, June 1979. [Online]. Available: https: //doi.org/10.2118/6845-PA

[40] J. H. Clint, Surfactant aggregation, 1st ed. Springer Netherlands, 1992.

[41] P. Somasundaran and L. Huang, "Adsorption behavior of surfactant mixtures at solid-liquid interface," Polish Journal of Chemistry, vol. 71, pp. 568-582, 1997.

[42] J. Novosad, B. Mainj, and A. Huang, "Retention of foam-forming surfactants at elevated temperatures," Journal of Canadian Petroleum Technology, vol. 25, no. 3, May 1986. [Online]. Available: https://doi.org/10.2118/86-03-04

[43] E. Delamaide, A. Cuenca, and M. Chabert, "State of the art review of the steam foam process," in SPE Latin America and Caribbean Heavy and Extra Heavy Oil Conference, Lima, Peru, 2016.

[44] W. Renpu, "Basis of well completion engineering," in Advanced Well Completion Engineering, W. Renpu, Ed. Miami, USA: Gulf Professional Publishing, 2011, pp. 1-74.

[45] M. Bavlere, B. B. Bazin, and C. Noik, "Surfactants for EOR: Olefin sulfonate behavior at high temperature and hardness," SPE Reservoir Engineering, vol. 3, no. 2, May 1988. [Online]. Available: https://doi.org/10.2118/14933-PA

[46] M. Baviere, B. Bazin, and J. C. Miléo, “Physicochemical properties of sulfonated fatty acid esters for oil recovery by surfactant flooding," Colloids and Surfaces, vol. 52, 1991. [Online]. Available: https://doi.org/10.1016/0166-6622(91)80023-H

[47] R. Tabary, B. Bazin, F. Douarche, P. Moreau, and F. Oukhemanou, "Surfactant flooding in challenging conditions: Towards hard brines and high temperatures," in SPE Middle East Oil and Gas Show and Conference, Manama, Bahrain, 2013, pp. 10-13.

[48] T. Amirianshoja, R. Junin, A. K. Idris, and O. Rahmani, "A comparative study of surfactant adsorption by clay minerals," Journal of Petroleum Science and Engineering, vol. 101, January 2013. [Online]. Available: https://doi.org/10.1016/j.petrol.2012.10.002

[49] X. Yu, S. Li, and S. Li, Eds., Clastic Hydrocarbon Reservoir Sedimentology, ser. Advances in Oil and Gas Exploration \& Production. Cham, Switzerland: Springer International Publishing, 2018.

[50] S. Xu and S. A. Boyd, "Cationic surfactant adsorption by swelling and nonswelling layer silicates," Langmuir, vol. 11, no. 7, July 1 1995. [Online]. Available: https://doi.org/10.1021/la00007a033

[51] M. J. Sánchez, M. C. Dorado, C. del Hoyo, and M. S. Rodríguez, "Influence of clay mineral structure and surfactant nature on the adsorption capacity of surfactants by clays," Journal of Hazardous Materials, vol. 150, no. 1, January 15 2008. [Online]. Available: https://doi.org/10.1016/j.jhazmat.2007.04.093

[52] P. A. Winsor, Solvent properties of amphiphilic compounds. London, England: Butterworth's Scientific Publications, 1954.

[53] R. L. Reed and R. N. Healy, "Some physicochemical aspects of microemulsion flooding: A review," in Improved Oil Recovery by Surfactant and Polymer Flooding, D. O. Shah and R. S. Schecheter, Eds. Academic Press, 1977, pp. 383-347.

[54] A. Lamarque and et al, Fundamentos Teórico-Prácticos de Química Orgánica, 1st ed. Argentina: Encuentro Grupo Editor, 2008.

[55] I. J. Lin and L. Marszall, "Partition coefficient, HLB and effective chain length of surface-active agents," in Progress in Colloid and Polymer Science, C. Papadakis, A. M. Schmidt, and F. Kremer, Eds. Springer, 2007, pp. 99-104.
[56] R. C. Pasquali, N. Sacco, and C. Bregni, "The studies on hydrophilic-lipophilic balance (HLB): Sixty years after William C. Griffin's pioneer work (1949-2009)," Latin American Journal of Pharmacy, vol. 28, no. 2, pp. 313-317, Jan. 2009.

[57] A. Verma, G. Chauhan, and K. Ojha, "Characterization of a-olefin sulfonate foam in presence of cosurfactants: Stability, foamability and drainage kinetic study," Educación Química UNAM, vol. 264, August 15 2018. [Online]. Available: https://doi.org/10.1016/j. molliq.2018.05.061

[58] K. Chan and D. Shah, "The effect of surfactant partitioning on the phase behavior and phase inversion of the middle phase microemulsions," in SPE Oilfield and Geothermal Chemistry Symposium, Houston, Texas, 1979.

[59] A. F. Belhaj and et al, "Experimental investigation of surfactant partitioning in Pre-CMC and Post-CMCregimes for enhanced oil recovery application," Energies, vol. 12, no. 12, 2019. [Online]. Available: https://doi.org/10.3390/en12122319

[60] Y. H. Kim and D. T. Wasan, "Effect of demulsifier partitioning on the destabilization of water-in-oil emulsions," Industrial \& Engineering Chemical Research, vol. 35, no. 4, April 9 1996. [Online]. Available: https://doi.org/10.1021/ie950372u

[61] C. Yuan and et al, "The effects of interfacial tension, emulsification and surfactant concentration on oil recovery in surfactant flooding process for high temperature and high salinity reservoirs," Energy Fuels, vol. 29, no. 10, September 2015. [Online]. Available: https://doi.org/10.1021/acs.energyfuels.5b01393

[62] A. F. Belhaj and et al, "Partitioning behaviour of novel surfactant mixture for high reservoir temperature and high salinity conditions," Energy, vol. 198, May 1 2020. [Online]. Available: https://doi.org/10. 1016/j.energy.2020.117319

[63] M. S. Kamal, M. S. Hussein, and A. S. Sultan, "Review on surfactant flooding: Phase behavior, retention, IFT, and field applications," Energy Fuels, vol. 31, no. 8, July 2017. [Online]. Available: https://doi.org/10.1021/acs.energyfuels.7b00353

[64] M. G. Aarra, H. Hoiland, and A. Skauge, "Phase behavior and salt partitioning in two- and three-phase anionic surfactant microemulsion systems: Part I, phase behavior as a function of temperature," Journal of Colloid and Interface Science, vol. 215, no. 2, July 15 1999. [Online]. Available: https://doi.org/10.1006/jcis.1999.6227

[65] R. C. Pasquali, M. P. Taurozzi, and C. Bregni, "Some considerations about the hydrophilic - lipophilic balance system," International Journal of Pharmaceutics, vol. 356, no. 1-2, June 2008. [Online]. Available: https://doi.org/10.1016/j.ijpharm.2007.12.034

[66] A. Graciaa and et al, "The partitioning of complex surfactant mixtures between oil/water/microemulsion phases at high surfactant concentrations," Energies, vol. 93, no. 2, June 1983. [Online]. Available: https://doi.org/10.1016/0021-9797(83)90431-9

[67] L. L. Handy, J. O. Amaefule, V. M. Ziegler, and I. Ershaghi, "Thermal stability of surfactants for reservoir application," Society of Petroleum Engineers Journal, vol. 22, no. 5, October 1982. [Online]. Available: https://doi.org/10.2118/7867-PA

[68] H. P. Angstadt and H. Tsao, "Kinetic study of the decomposition of surfactants for EOR," SPE Reservoir Engineering, vol. 2, no. 4, November 1987. [Online]. Available: https://doi.org/10. 2118/12662-PA

[69] R. D. Shupe and T. D. Baugh, "Thermal stability and degradation mechanism of alkylbenzene sulfonates in alkaline media," Journal of Colloid and Interface Science, vol. 145, no. 1, August 1991. [Online]. Available: https://doi.org/10.1016/0021-9797(91)90115-0 